Pau Bori ${ }^{1}$

Universitat de Belgrad

Facultat de Filologia

Departament d'Estudis Ibèrics
UDK: 371.3::811.134.1

https://doi.org/10.18485/imp.2017.ch.10

\title{
EVOLUCIÓ DELS LLIBRES DE TEXT DE CATALÀ PER A NO CATALANOPARLANTS ADULTS DES D'UNA PERSPECTIVA SOCIOECONÒMICA
}

Aquest article presenta l'evolució dels materials didàctics de català adreçats a immigrants adults en relació amb el seu context històric, polític i socioeconòmic. L'estudi assenyala dos moments claus en la història dels llibres de text de català. El primer ens situa als anys vuitanta, una dècada de grans transformacions a l'estat espanyol després de la mort de Franco i l'ingrés a la Comunitat Econòmica Europea. El llibre de text més popular d'aquest període és el curs multimèdia Digui, Digui, promogut pel govern català sota els auspicis del Consell d'Europa.

El segon moment clau ens porta als primers anys del segle XXI. L'estat espanyol va experimentar aleshores un ràpid creixement econòmic basat en l'aplicació de polítiques neoliberals que va requerir l'arribada de treballadors estrangers sobretot per als sectors de la construcció i el turisme. L'augment d'immigrants a Catalunya va propiciar un major nombre d'estudiants de català i també la multiplicació llibres de text de català per a no catalanoparlants adults. A la vegada, però, en aquests últims anys s'ha viscut un accelerat procés d'estandardització, homogeneïtzació i centralització dels llibres de text de català, en el sentit que tots parteixen d'uns mateixos plantejaments: s'adeqüen als nivells del Marc Europeu Comú de Referència del Consell d'Europa i proposen un ensenyament comunicatiu d'una llengua pràctica al servei dels interessos de l'economia neoliberal.

Paraules clau: Llibres de text; català com a segona llengua; ensenyament de llengües estrangeres; neoliberalisme; immigració.

\section{Introducció}

El propòsit d'aquest article és explicar l'evolució dels llibres de text de català com a segona llengua o com a llengua estrangera a la llum del 
context polític, social i econòmic d'on han sorgit. Davant d'un tractament convencional que aïlla l'estudi dels materials didàctics del seu context macro, en aquest treball considerem que l'anàlisi de l'evolució dels llibres de text catalans seria incompleta si no l'inserim dins la realitat socioeconòmica que els ha originat.

Aquest plantejament parteix de la idea que els materials didàctics són artefactes culturals del seu temps, com qualsevol altra activitat humana. És a dir, no són uns productes nascuts enmig del no-res, sinó que estan situats en un moment i un lloc determinats de la història i, en conseqüència, estan influenciats pel context socioeconòmic, polític i històric on s'han concebut (Littlejohn 2013).

La noció que tota activitat humana està situada socialment i temporal, evidentment, no és nova. Com és prou sabut, Karl Marx ja va assenyalar la necessitat de posar en relació les activitats humanes i la vida social amb el seu context històric. En l'àmbit de l'educació i les ciències socials, autors com Antonio Gramsci, els pensadors de l'Escola de Frankfurt, Pierre Bourdieu, Michel Foucault, Paolo Freire, Michael Apple o Henry Giroux han investigat diversos fenòmens socials des de diferents perspectives, però tenint sempre molt en compte el context macro del seu objecte d'estudi. En el camp específic de l'ensenyament de llengües estrangeres, existeix en aquests darrers anys un creixent interès per reorientar la interdisciplinarietat característica de la lingüística aplicada vers un enfocament d'inspiració marxista que se centri en les bases materials i econòmiques de l'activitat humana i la vida social a l'hora d'estudiar aspectes relacionats amb la llengua (Block, Gray i Holborow 2012).

Aquest estudi assenyala dos moments claus en l'evolució dels Ilibres de text de català. El primer ens situa a la dècada dels vuitanta, coincidint amb la internacionalització de l'economia espanyola i la integració de l'estat espanyol a la Comunitat Econòmica Europea (més endavant, Unió Europea). El segon moment clau ens porta als primers anys del segle XXI, en el marc de la globalització neoliberal.

\section{Anys vuitanta}

La dècada dels vuitanta, després de la mort del dictador Franco el 1975 i l'anomenada transició cap a una democràcia parlamentària, és un 
EVOLUCIÓ DELS LLIBRES DE TEXT DE CATALÀ PER A NO CATALANOPARLANTS ADULTS DES D'UNA...

període de grans transformacions a l'estat espanyol, i també a Catalunya. L'estat espanyol malda aleshores per sortir de la crisi econòmica dels setanta, causada per l'esgotament de la modalitat fordista del franquisme (l'anomenat 'desarrollismo'), els dèficits estructurals d'una economia fortament dependent dels sectors del turisme i la construcció, i les repercussions de la crisi internacional del petroli de 1973.

A la segona meitat de la dècada dels vuitanta es viu una certa recuperació econòmica impulsada pel primer experiment de creixement per la via d'una forta revalorització dels actius financers i immobiliaris (Rodríguez i López 2011: 41), coincidint amb l’ingrés de l'estat espanyol el 1986 a la Comunitat Econòmica Europea. Entre 1986 i 1991, l'economia espanyola experimenta un procés d'incorporació accelerada al sistema econòmic capitalista occidental, amb la integració al mercat comú europeu i l'arribada d'inversions estrangeres, que propicien un augment del consum intern però no pas una disminució de les desigualtats socials. És en aquest període quan es posen els fonaments d'un nou model capitalista, basat en polítiques neoliberals de suport al capital privat, l'afebliment del sector públic, la potenciació dels mecanismes del mercat, la creixent importància del capital financer i especulatiu, i canvis radicals en l'organització del món del treball (Etxezarreta 1991). El govern del PSOE, amb la complicitat dels principals agents econòmics espanyols (sindicats i patronal), va apostar per l'obertura econòmica exterior amb l'argument que facilitaria la modernització de l'economia espanyola i, sobretot, la consolidació d'una democràcia encara molt feble. La voluntat europeista va significar una acceptació passiva per part de l'estat espanyol de tots els condicionants econòmics i polítics que venien de l'exterior. Com explica Etxezarreta (1991: 57), les forces internacionals i 'el mercat' són els que van guiar la integració de l'estat espanyol al bloc capitalista occidental.

És en el marc d'aquest context econòmic i polític quan la Generalitat de Catalunya, després de quatre dècades de persecució del català per part de la dictadura franquista, impulsa polítiques per recuperar àmbits d'ús per a la llengua catalana. Entre els seus objectius, les polítiques lingüístiques de la Generalitat inclouen també l'ensenyament del català a no catalanoparlants adults. Els principals destinataris són immigrants (o els seus fills) d'origen espanyol i majoritàriament de primera llengua cas- 
tellana que havien arribat a Catalunya entre 1950 i 1975, i no havien tingut l'oportunitat d'aprendre el català sota la dictadura franquista. Amb aquest objectiu, la Generalitat impulsa a principis dels vuitanta classes de català per a població castellanoparlant, que es concentrava sobretot en zones urbanes i, en general, era de classe treballadora. A la pràctica, però, el grup més important d'estudiants no catalanoparlants de català va ser el format per treballadors de l'administració pública majoritàriament de llengua materna castellana, pertanyents a un extracte social acomodat, i que en molts casos cercaven un certificat de català per consolidar o millorar la seva situació laboral.

Amb l'inici de les classes de català per a no catalanoparlants adults, les institucions catalanes aposten per seguir les propostes del Consell $\mathrm{d}^{\prime}$ Europa $^{2}$ per a un ensenyament comunicatiu de les llengües estrangeres. S'organitzen, per exemple, cursos de formació de professorat de català centrats en el mètode comunicatiu, en com dur-lo a l'aula i en com utilitzar materials que segueixen aquest enfocament. Com succeeix en la majoria de llengües europees en aquests anys, també s'adapta al català The Treshold Level (Van Ek 1975) del Consell d'Europa, un document que proposa que el principal objectiu de l'aprenentatge d'una llengua és la comunicació relacionada amb els temes del dia a dia. Tot i que la versió catalana d'aquest document, titulada Nivell Ilindar per a la llengua catalana (Mas et al. 1992), no sortiria publicada fins uns anys més tard, el primer esborrany del document ja es va enllestir a principis de 1983.

Segurament, però, el que més va ajudar a expandir les idees del Consell d'Europa a Catalunya va ser la difusió del popular curs multimèdia de català per a no catalanoparlants adults Digui, digui, elaborat seguint el plantejament del Nivell llindar.

Les recomanacions del Consell d'Europa van tenir una ràpida acceptació en l'àmbit del català per a no catalanoparlants adults, com de fet va succeir en la majoria de països europeus. No hi va haver un debat sobre si aquestes propostes ideades inicialment per a l'anglès s'adaptaven a les circumstàncies catalanes. La justificació d’aquesta ràpida recepció i poste-

2 Organització política fundada el 1949 amb seu a Estrasburg que avui dia integra 47 estats, incloent-hi tots els membres de la Unió Europea. Ha desenvolupat nombrosos projectes educatius i d'ensenyament de llengües modernes. 
EVOLUCIÓ DELS LLIBRES DE TEXT DE CATALÀ PER A NO CATALANOPARLANTS ADULTS DES D'UNA...

rior expansió de les propostes del Consell d'Europa per a l'ensenyament del català a no catalanoparlants adults podria ser explicada pel context sociolingüístic català, el d'una llengua històricament minoritzada amb poc poder polític i econòmic que afavoreix l'interès per afiliar-se a una política general, en aquest cas d'àmbit europeu. A més, la integració de l'estat espanyol primer a I'OTAN i després a la Comunitat Econòmica Europea va fer que el govern català, igual que el govern central, maldés per adaptar-se als plantejaments econòmics i polítics (també en l'àmbit educatiu) de les democràcies europees occidentals. La voluntat europeista dels poders politics catalans, com també succeïa en l'àmbit espanyol, va fer que totes les directrius que venien de l'exterior fossin acceptades d'una forma passiva.

D’aquesta manera, al llarg de les dècades dels vuitanta i els noranta, la tecnocràcia europea (el Consell d'Europa) aconsegueix implantar les seves propostes en l'ensenyament de català per a adults, al mateix temps que en els sistemes educatius de la Unió Europea, incloent-hi l'espanyol, $s^{\prime}$ hi introdueixen unes idees molt similars. Es tracta d'uns plantejaments que promouen unes competències cognoscitives i comunicatives en l'educació que s'adeqüen als interessos del mode de producció capitalista postindustrial (Jódar i Gómez 2007) que aleshores es gestava a Europa en el qual la interacció i la comunicació esdevindrien valors en alça en la nova organització del treball (Virno 2003). Segons apunten diversos autors crítics, rere aquestes idees, tot i presentar-se sovint com si fossin neutres o fins i tot alliberadores, hi ha uns determinats interessos: millorar les economies nacionals estrenyent els llaços entre educació, ocupació, productivitat i comerç; mesurar els resultats dels estudiants d'acord amb les habilitats i competències relacionades amb el nou món laboral; i exercir un major control sobre el contingut dels currículums i l'avaluació (O’Neill 1995: 9).

\subsection{El Digui, digui}

De tots els materials didàctics de les dècades dels vuitanta i noranta, el Digui, digui és sens dubte el més popular. Es tracta d'un curs promogut per la Generalitat de Catalunya a imatge i semblança del curs multimèdia d'anglès Follow me creat per la BBC amb el suport del British Council. Durant tot el procés d'elaboració d'aquest material, l'equip català va 
comptar amb l'assessorament d'un grup d'experts del Consell d'Europa (Trim 1992). El Consell d’Europa, segons explica Marí (1986), va incloure aquest material com a experiència pilot dins el seu Projecte 12, Learning and Teaching Modern Languages for Communication.

Es va dividir en dos nivells: Digui, digui... Curs de català per a no catalanoparlants adults. Primer nivell (Mas et al. 1984) i Digui, digui... Curs de català per a no catalanoparlants adults. Segon nivell (Mas et al. 1985). Cadascun dels nivells consta del llibre de l'alumne, el llibre d'exercicis, el llibre del professor, el llibre de l'autoaprenent, i una col·lecció d'àudios amb cassetes i de vídeos. L'elaboració d'aquest material va significar una important inversió econòmica per part de la Generalitat de Catalunya, d'uns 150 milions de les antigues pessetes, segons una informació apareguda aleshores a El País (Galceran 1984).

El curs segueix un síl·labus nocional funcional i, com s'explica al Ilibre del professor del primer nivell, té l'objectiu de dotar l'alumnat d'una competència comunicativa real $\mathrm{i}$ immediata:

Per explicar-ho ben planament: aquí no interessa tant que l'aprenent domini la morfologia verbal del català o els seus mecanismes de pronominalització; ni tan sols que pugui accentuar correctament una paraula com per exemple 'albergínia', ni que sàpiga que aquesta paraula vol dir 'berenjena' o 'aubergine'; ens interessa que, si ha d'anar a comprar albergínies, pugui realitzar tots els actes de paraula necessaris per dur a terme en català aquest acte comercial: demanar a quin preu van, dir com les vol, quantes en vol, fer valoracions de preu o de qualitat, etc. (Llobera et al. 1989: 4)

Paral-lelament, Digui, digui es va adaptar per ensenyar la llengua a través de la premsa, dos canals de televisió (TV3 i el segon canal de TVE) i diferents emissores de ràdio:

Per televisió es van emetre els vídeos del curs en forma de sèrie televisiva diària. A la premsa es va publicar una pàgina setmanal amb activitats lúdiques i concursos relacionats amb el context social i cultural i amb el contingut del mateix diari. El programa de ràdio disposava d'un professor que presentava activitats en format radiofònic i que resolia qüestions relacionades amb el curs plantejades tant per alumnes com per professors. (Gimeno 2012: 5) 
EVOLUCIÓ DELS LLIBRES DE TEXT DE CATALÀ PER A NO CATALANOPARLANTS ADULTS DES D’UNA...

Fruit de la seva presència als mitjans de comunicació de massa, el Digui, digui ben aviat va aconseguir una gran popularitat dins la societat catalana. De mica en mica, també es va convertir en el material més utilitzat per a l'ensenyament de català per a adults als territoris de parla catalana, sobretot gràcies a l'impuls que li donaven les institucions catalanes que van fer múltiples cursos per ensenyar al professorat com utilitzar el Digui, digui a l'aula. A banda d'aquest suport institucional, la professora de català Eulàlia Torras apunta d'altres motius que podrien també explicar la gran utilització d'aquest materials en les aules de català per a no catalanoparlants adults:

en part perquè és el mètode promogut directament des de la Generalitat, en part perquè és el que compta amb més complements que li afegeixen varietat; possiblement també perquè ofereix una orientació comunicativa nocional funcional i una progressió molt ben controlada. (Torras 1992: 294 )

Més endavant, el Digui, digui també es va començar a utilitzar en les classes de català de moltes universitats angleses, alemanyes, italianes i franceses, entre d'altres, malgrat estar pensat per a un públic castellanoparlant resident a Catalunya.

A mitjan de la dècada dels noranta, després de diverses edicions i per encàrrec de la Generalitat de Catalunya, els autors del Digui, digui presenten una versió revisada de l'obra. A més, també amb el suport del govern català, en aquells anys s'editen adaptacions d'aquest curs per a estudiants de català que tenen com a llengua materna el francès, l'anglès, l'alemany i l'italià. D’aquesta manera, el Digui, digui tindrà un Ilarga vida dins les aules d'ensenyament de català a no catalanoparlants adults que arribarà fins els primers anys del segle XXI. La darrera reimpressió d’algun dels llibres de text del Digui, digui data de 2005.

Amb la introducció a la dècada dels vuitanta de les polítiques lingüístiques del Consell d'Europa a Catalunya i la utilització del Digui, digui comença un procés que, amb el temps, portarà a una major centralització i estandardització dels materials de català per a no catalanoparlants adults. En disposar d'un material amb tants recursos com el Digui, digui, el professorat de català ja no tindrà tanta necessitat de crear els seus propis materials per a l'aula, com passava per exemple a la dècada dels 
setanta o durant la primera meitat dels vuitanta. A més, després de l'aparició del Digui, digui i amb la publicació posterior d'altres productes similars, els materials didàctics comercials cada vegada tindran més influència en el procés d'aprenentatge: quina llengua s'aprèn, de quina forma, amb quins continguts $i$, fins i tot, la manera com s'interactua dins l'aula.

L'organització de les unitats, els continguts i, en general, l'esperit del Digui, digui (ensenyament comunicatiu d'una llengua pràctica) tindrà continuïtat, malgrat algunes modificacions més aviat formals, en tots els IIibres de text posteriors.

\subsection{Retalls}

Malgrat que el Digui, digui és el material més utilitzat en l'ensenyament de català a no catalanoparlants adults des de la seva publicació a mitjan dels vuitanta fins als primers anys d'aquest segle, és rellevant també descriure breument un dels altres llibres de text d'aquest període que presenta un plantejament diferent.

Es tracta de Retalls. Textos i exercicis de l'aprenentatge del català (Albó et al. 1980), nascut de l'experiència de les autores com a professores de català a no catalanoparlants a la Universitat de Barcelona i que va viure fins a 7 edicions. Aquesta obra, gestada abans de la recepció a Catalunya de les polítiques del Consell d'Europa, es diferencia de la resta de llibres per proposar una aproximació a la llengua a través de fragments literaris d'autors catalans. La voluntat d'aquesta obra és ensenyar una llengua que vagi més enllà de la funció instrumental, oposant-se als plantejaments hegemònics en l'època. Les autores ho expliquen amb claredat en la presentació:

Una llengua, concebuda només com a eina-instrument-vehicle d'expressió, pot reduir-se a un vocabulari bàsic, unes estructures fonamentals i unes fórmules quasi matemàtiques. Aleshores només cal introduir-la en un ordenador -o en un cap mitjanament intel-ligent- i obtenir-ne la traducció simultània. Aquesta llengua eina funcional és molt útil per viatjar, per fer intercanvis comercials $\mathrm{i}$, fins i tot, per conquerir i colonitzar pobles.

Però nosaltres voldríem donar quelcom més que una llengua vehicular. Creiem que tota llengua reflecteix la manera de concebre la vida i 
EVOLUCIÓ DELS LLIBRES DE TEXT DE CATALÀ PER A NO CATALANOPARLANTS ADULTS DES D'UNA...

l'entorn del poble que l'ha anada creant i, com que estimem el nostre poble i la nostra cultura, ens sap greu donar-ne només un extracte o una mostra funcional que serveixi per preguntar quant val això i allò, a quina hora surt l'avió, i si us agrada la sopa de peix. El nostre desig i propòsit és comunicar-la d'una manera més plena i viva, intentant donar unes pistes de comprensió de l'esperit del nostre poble. (Albó et al. 1980: 129)

Es tracta, doncs, d'un plantejament diametralment oposat d'aquell exposat en la cita anterior del Digui, digui on, amb l'exemple de l'albergínia, s'explicava que un dels principals objectius era el de resoldre les transaccions corrents del dia a dia.

Retalls, que s'obre amb un pròleg d'Antoni M. Badia i Margarit, a l'edició de 1980 s'estructura en dues grans parts. La primera és un recull de textos literaris de diferents estils i gèneres, organitzats per temes, mentre que a la segona part es proposen una sèrie d'exercicis per treballar els textos literaris.

La proposta de Retalls demostra que hi havia d'altres possibles enfocaments d'ensenyar llengua, allunyats del mètode comunicatiu que aleshores començava a despuntar a Europa. L'enfocament de Retalls, però, no va tenir continuïtat amb d'altres llibres de text de català. Amb la irrupció del mètode comunicatiu i les polítiques lingüístiques del Consell d’Europa a Catalunya, es va apostar per ensenyar una llengua eminentment pràctica, tot sovint a partir de situacions trivials, la qual cosa va provocar que la literatura passés a ocupar un paper marginal als nous materials didàctics de català per a no catalanoparlants adults.

\section{Segle XXI}

La dècada dels noranta va suposar un punt d'inflexió per a l'estat espanyol. Es va desenvolupar un model econòmic cada vegada més neoliberal (privatització d'empreses públiques, implementació de les polítiques del Tractat de Maastricht de 1992, la llei del sòl de 1998, desregulació bancària, especulació financera) que propiciaria una crescuda del PIB basada sobretot en els sectors del turisme i la construcció. Fou un creixement econòmic sustentat en uns fonaments molt poc sòlids $i$ en 
una gran dependència dels fluxos de capitals a nivell global (Etxezarreta et al. 2012). Aquest auge econòmic va propiciar la creació de nous llocs de treball, però també un major endeutament, una gran dependència de les entitats creditícies, més precarietat laboral i un deteriorament ambiental causat per les urbanitzacions extensives.

Com a resultat d'aquest creixement econòmic que va ser especialment important entre el 2000 i el 2007, hi va haver una forta demanda de mà d'obra barata per atendre la indústria turística, els serveis, l'atenció de persones grans en l'àmbit domèstic, l'agricultura extensiva i sobretot la intensa activitat en el sector la construcció.

Al mateix temps, les diferències entre els països rics i els pobres seguien creixent a nivell global, a causa en gran mesura de l'expansió de les polítiques neoliberals arreu del planeta: major internacionalització de les finances, el capital i les empreses dels països rics cap a zones pobres del planeta; afebliment del paper econòmic dels estats i enfortiment de la pressió d'organismes supranacionals com el Fons Monetari Internacional i el Banc Mundial; reducció de les barreres aranzelàries; i en definitiva, com conclou García Viamontes (2010), el saqueig de les riqueses dels països pobres per part de les nacions poderoses.

La conjunció d'aquests dos factors provoca un gran augment d'immigració extracomunitària a Catalunya, especialment en la primera dècada del segle XXI. Catalunya va passar dels poc més de 6 milions d'habitants el 2000 a superar els 7' 5 milions en els darrers anys. L'any 2000 els estrangers empadronats a Catalunya representaven tot just el 2'9\% de la població total, mentre que el 2010 van arribar a representar el 15,95\% del conjunt de la població (Idescat 2016) ${ }^{3}$.

La crisi econòmica actual - desfermada per l'esclat de la bomboIla financera i immobiliària de 2008 que va posar en evidència la feblesa del creixement econòmic espanyol de principis del segle XXI- ha afectat especialment aquest col-lectiu d'immigrants estrangers, que pateixen pobresa, precarietat laboral, problemes d’accés a l'habitatge i a la feina.

3 Als darrers anys el nombre de persones estrangeres residents a Catalunya s'ha reduït una mica, arran de les conseqüències de l'actual crisi econòmica capitalista que afecta especialment els col-lectius d'immigrants. Segons les darreres dades disponibles, corresponents a l'any 2015 , el número de ciutadans no espanyols empadronats a Catalunya representava el 13,69\% de la població total (Idescat 2016). 
EVOLUCIÓ DELS LLIBRES DE TEXT DE CATALÀ PER A NO CATALANOPARLANTS ADULTS DES D’UNA...

El creixement de la població d'origen estranger a Catalunya va propiciar un augment d'estudiants als cursos de català per a adults no catalanoparlants. Una prova fefaent n'és l'increment d'inscripcions durant la primera dècada d'aquest segle al Consorci per a la Normalització Lingüística (CPNL), el principal centre d'ensenyament de català a no catalanoparlants adults. Des del curs 2000-2001, que el CPNL va tenir un total de 43.032 inscripcions, el nombre d'inscrits va anar augmentant any rere any fins arribar a un màxim de 127.807 inscripcions durant el curs 2009-2010 (CPNL 2012). En els darrers anys el nombre d'inscripcions al CPNL s'ha reduït a causa de la crisi econòmica i les consegüents disminució de la migració a Catalunya i la partida de molts immigrants. ${ }^{4}$

Coincidint amb l'inici d'aquesta gran onada migratòria d'origen estranger i el progressiu augment d'estudiants adults de català no catalanoparlants, les institucions catalanes, com les de molts altres països europeus, van traduir el Common European Framework of References for Languages (Consell d'Europa 2001) amb el títol català de Marc Europeu Comú de Referència per a les llengües (MECR 2003). Aquest document proposa un sistema unitari per a l'ensenyament de llengües estrangeres que uniformaria els síl·labus i els dissenys de currículums, l’avaluació i els exàmens, els materials didàctics, i en gran mesura, la manera d'ensenyar llengües estrangeres a Europa i fora d'aquest continent.

Certes parts del MECR, especialment la definició dels nivells i els seus descriptors, van tenir una acollida excepcional a Catalunya. Des de la seva publicació i fins avui dia, els nivells de referència del MECR s'han convertit en elements indiscutibles a l'hora de fixar els nivells dels cursos de català tant d'institucions públiques com privades, dels exàmens oficials de llengua catalana i també dels materials didàctics de català.

En el moment de la recepció del MECR a Catalunya, els plantejaments del Consell d'Europa se solien acatar sense discussió, ja que no hi havia tantes veus crítiques sobre les seves propostes. Avui dia, en canvi, aquesta assumpció tan absoluta de les recomanacions del Consell d'Europa i, en particular del MECR, sí que ha provocat crítiques en l'àmbit

$4 \quad$ L'any 2014, el darrer del qual disposem de dades, hi va haver un total de 67.465 inscripcions als cursos de català per a adults del Consorci, la majoria de les quals van ser per als cursos de nivell inicial i bàsic (CPNL 2014). El 61,3\% del total de les persones inscrites al Consorci el 2014 eren nascudes a l'estranger (CPNL 2014) 
internacional de cada vegada més investigadors con recull la tesi doctoral de Valax (2011).

Juntament amb el MECR, els programes i les programacions de llengua catalana per a l'ensenyament d'adults, editats per la Generalitat de Catalunya a partir de 2001, són els documents oficials que més influència han tingut en els enfocaments i els continguts de cursos i materials didàctics de català per a no catalanoparlants adults de la darrera dècada. Tots aquests programes i programacions de català de la Generalitat tenen en comú que segueixen molt de prop les recomanacions del MECR o, en alguns casos, esborranys o treballs previs del Consell d'Europa. Per tant, es proposa un síllabus nocional funcional per a un ensenyament comunicatiu del català a través del treball per tasques i un èmfasi en l'aprenentatge d'una llengua instrumental i d'ús quotidià que permeti l'aprenent comunicar-se en certs àmbits i sobre uns temes determinats.

Amb la recepció del MECR a principis d'aquest segle es culmina el procés iniciat a la dècada dels vuitanta d'aplicar les polítiques educatives del Consell d'Europa en l'ensenyament del català a no catalanoparlants adults. La proposta d'ensenyament de llengües del Consell d'Europa ha esdevingut des d'aleshores hegemònica en l'àmbit de l'ensenyament de català a no catalanoparlants adults, i evidentment també en els seus materials didàctics.

Les polítiques europees d'ensenyament de llengües estrangeres han anat agafades de la mà de les estratègies d'educació general per adequar-se al sistema econòmic, polític i social del neoliberalisme vigent a l'Europa contemporània. Dit d'una altra manera, els plantejaments del Consell d'Europa s'emmarquen dins una reforma més àmplia de l'educació per posar-la al servei de les necessitats del sistema capitalista neoliberal del segle XXI. L'esperit d'aquesta nova concepció de l'educació, segons diversos autors crítics (Torres 1991; Luke 2006; Hirtt 2009), es caracteritza per la mercantilització del sistema educatiu i la seva submissió a la productivitat dels mercats. En l'àmbit de les segones llengües, el MECR, a la vegada que ha facilitat a professorat i dissenyadors de curosos l'elaboració dels seus programes, ha esdevingut també un instrument per promoure una estandardització cultural d'acord amb els principis neoliberals, amb l'objectiu de formar treballadors per al bon funcionament dels negocis internacionals (Bouffoy-Bastick 2015). 
EVOLUCIÓ DELS LLIBRES DE TEXT DE CATALÀ PER A NO CATALANOPARLANTS ADULTS DES D’UNA...

Com expliquen Jódar i Gómez (2007: 396-400), les reformes educatives de caire neoliberal s'han apropiat, d'una forma "cínica i contrarevolucionària", de part del vocabulari dels col-lectius socials crítics i antiautoritaris de les dècades dels seixanta i setanta, com ara la llibertat, l'autonomia o la defensa d'individus flexibles i plurals. El nou règim capitalista ha fagocitat les idees de les pedagogies progressistes de fa quatre dècades que pretenien promoure una menor rigidesa i una major creativitat en els sistemes educatius per posar-les al servei de la desregulació laboral i social que promou el neoliberalisme (Jódar i Gómez 2003). Un dels casos més paradigmàtics d'aquesta apropiació seria el concepte d'autonomia, inicialment relacionat amb la idea humanista d'estudiants no sotmesos a un control exterior, que ara s'associa fonamentalment a la capacitat de l'individu per concebre's a si mateix com a una empresa que d'una forma creativa i flexible pren decisions per progressar independentment (Kaščák i Pupala 2011: 150).

\subsection{Boom de llibres de text}

Amb l'augment d'estudiants estrangers de català a Catalunya i la major implantació de polítiques neoliberals al conjunt de l'estat espanyol, hi ha un increment espectacular de materials didàctics de català. Es publiquen noves col-leccions de llibres de text, cursos per aprendre català en línia, materials per a grups específics, i una gran varietat de recursos complementaris: llibres de lectura fàcil, diccionaris bilingües, llibres de vocabulari, gramàtiques didàctiques, guies de conversa, a més d'una quantitat creixent de recursos digitals per aprendre català per internet.

La majoria de col-leccions llibres de text de català del segle XXI presenten grans similituds, tant a nivell formal com de contingut. Solen comptar amb diversos materials complementaris (audicions, llibres d'exercicis, guia del professor), moltes instruccions (detallades sovint en una guia del professor) i els llibres de l'alumne acostumen a tenir seqüències força semblants, organitzades a partir del treball per tasques i un enfocament comunicatiu per a l'aprenentatge d'una llengua pràctica. El contingut dels llibres, com expliquem en detall en un altre treball (Bori 2015: 295-426), sol centrar-se en estils de vida característics de classes mitjanes i altes 
occidentals, amb la presentació de múltiples valors i pràctiques neoliberals des d'una perspectiva en general positiva, com a fenòmens naturals. Un altre denominador comú de totes les col-leccions dels llibres de text és fer constar en un lloc un lloc ben visible que segueixen els programes o les programacions de la de la Generalitat de Catalunya, i sobretot que tenen en compte els nivells del MECR.

Les editorials del Principat que han publicat en els darrers anys llibres de text adreçats a no catalanoparlants adults són Edicions Àlber, Castellnou, Barcanova, Publicacions de I'Abadia de Montserrat, Octaedro i Teide. El Centre de Normalització Lingüística de Barcelona també ha publicat entre 2008 i 2011 una col·lecció de llibres de text (formada per tres dossiers de nivell bàsic), que s'utilitza a les aules d'aquest centre a la capital catalana.

Als altres territoris de parla catalana, la producció de llibres de text per a no catalanoparlants adults ha estat significativament inferior que al Principat, però no pas inexistent. Al País Valencià, per exemple, hi ha les col-leccions D'ací i d'allà. Curs de Valencià de l'editorial Tabarca o Va de bo! de Bromera. A la Catalunya Nord ha aparegut el llibre Encara i sempre adreçat a un públic francòfon.

Fora dels territoris de parla catalana, també han aparegut alguns Ilibres de text, com per exemple un manual de català inicial en rus publicat el 2002 per l'editorial de la universitat Lomonóssov de Moscou (Anatólievna 2007), que es diferencia de la resta de materials contemporanis per tenir una orientació de l'ensenyament de la llengua més propera al mètode de gramàtica i traducció, que no pas als enfocaments comunicatius. A més, s'han publicat diversos llibres d'autoaprenentatge del català a partir de diferents idiomes.

\subsection{Parla.cat}

Un dels fenòmens característics de la nova economia del coneixement o la societat de la informació - conceptes estretament vinculats al gir econòmic neoliberal dels darrers anys - és el desenvolupament de les tecnologies de la informació i la comunicació (TIC en endavant) en àmplies esferes socials: des del món de les finances o la indústria a escala global, fins a l'àmbit de l'educació. Prodnik (2014) argumenta que les transformacions que comporta l'economia del coneixement (per exemple, la impor- 
EVOLUCIÓ DELS LLIBRES DE TEXT DE CATALÀ PER A NO CATALANOPARLANTS ADULTS DES D’UNA...

tància creixent de les TIC) s'emmarquen dins uns canvis molt més amplis de caire polític, econòmic i social. Des d'una perspectiva crítica, diversos investigadors (Hatcher i Hirtt 1999, Levidow 2006; Selwyn 2015) posen en relació el desenvolupament de l'educació amb TIC amb els imperatius del projecte econòmic neoliberal: promoure els valors del lliure mercat, l'individualisme, la concepció dels aprenents en tant que emprenedors, la competència entre estudiants, la flexibilitat, la mobilitat i la disminució del paper dels estats.

En el cas del català per a no catalanoparlants adults, aquests darrers anys han sorgit múltiples materials didàctics digitals, la majoria dels quals són accessibles de franc a través d'internet. El més conegut de tots és el portal en línia impulsat pel govern català, Parla.cat (Generalitat de Catalunya 2008). Ofereix cursos de llengua ajustats als nivells del MECR muntats en un entorn moodle i pensats per a l'aprenentatge per lliure o amb un tutor a distància.

La Generalitat va invertir més de 4 milions d'euros per posar en marxa aquesta plataforma. Informática El Corte Inglés (pertanyent a un dels grups empresarials més grans de l'estat espanyol) va obtenir la concessió per desenvolupar la part tècnica de la plataforma, mentre que un altra gran corporació, la multinacional Capgemini, va rebre l'encàrrec de crear la metodologia e-learning, els continguts, la programació i el disseny gràfic de Parla.cat.

Es tracta d'una plataforma enorme que consta de 4 nivells (bàsic, elemental, intermedi i superior) amb més de 4.000 exercicis i informació en 4 llengües diferents. Va entrar en funcionament el 2008, just en el moment de l'esclat de la bombolla immobiliària i financera a l'estat espanyol.

El nombre d'estudiants inscrits a aquesta plataforma és espectacular. El 2016 va superar els 200.000 inscrits (Generalitat de Catalunya 2016). Tanmateix, aquesta xifra no recull quantes de les persones inscrites han seguit realment algun dels cursos de Parla.cat ni tampoc en quina mesura han millorat els seus coneixements de llengua catalana amb l'ús d'aquests recursos.

Malgrat l'esperit innovador de Parla.cat, l'organització i el contingut de les unitats és molt semblant al de les col-leccions de llibres de text publicats als primers anys del segle XXI. Les úniques diferències remarcables són l'ús de vídeos i animacions (al costat de textos escrits i audicions) i la possibilitat d'accedir ràpidament a molts d'altres recursos didàctics en 
línia. L'esperit de la plataforma Parla.cat segueix, en el fons, una orientació comunicativa de l'aprenentatge de la llengua i les recomanacions del Consell d'Europa.

\section{Conclusions}

En aquest article hem explicat com els llibres de text de català per a no catalanoparlants adults han seguit les recomanacions del Consell d'Europa ja des de la dècada dels vuitanta, amb la publicació del popular curs multimèdia de català Digui, digui. La introducció de les propostes del Consell d'Europa a Catalunya es va produir en uns anys de major integració de l'estat espanyol al sistema econòmic europeu, marcats per una voluntat europeista dels poders polítics autòctons que va fer que totes les directrius que venien d'Europa fossin acceptades d'una forma passiva.

L'adopció de les recomanacions metodològiques del Consell d'Europa es consolida a la primera dècada del segle XXI, amb l'aplicació del MECR en l'àmbit del català a no catalanoparlants adults i l'elaboració de nous programes de català. Coincidint amb l'era de la globalització neoliberal, ha augmentat el nombre d'estudiants estrangers de català i s'han multiplicat les col-leccions de llibres de text. També s'han diversificat els formats dels materials didàctics de català, amb una major presència de recursos digitals. A la vegada, però, s'ha viscut un creixent procés d'estandardització, centralització i homogeneïtzació dels llibres de text de català, en el sentit que l'esperit del diferents materials didàctics és molt semblant. Tots s'adeqüen als nivells del MECR i a les propostes del Consell d'Europa i, en conseqüència, proposen un ensenyament comunicatiu d'una llengua pràctica i útil al servei dels interessos del nou ordre econòmic neoliberal.

\section{BIBLIOGRAFIA}

Albó, Montserrat, et al. Retalls. Textos $i$ exercicis de l'aprenentatge del català. Barcelona: Teide, 1980. Imprès.

Anatólievna, Marina. "La catalanística a Rússia". Jornades de catalanística a Praga Andorra: Biblioteca Andorrana Internacional, 2007. 67-71. Imprès. 
Block, David, John Gray and Marnie Holborow. Neoliberalism and applied linguistics. Londres / Nova York: Routledge, 2012. Print.

Bori, Pau. "Anàlisi crítica de llibres de text de català per a no catalanoparlants adults en temps de neoliberalisme". Tesi doctoral no publicada. Universitat Pompeu Fabra, Barcelona, 2015. Web. 05.5.2016. http://www.tdx.cesca.cat/handle/10803/350798

Boufoy-Bastick, Béatrice. "Rescuing language education from the neoliberal disaster: Culturometric predictions and analyses of future policy". Policy Futures in Education, Vol. 13, Núm. 4 (2015): 439-467. Print.

Consell d'Europa. Common european framework for languages: learning, teaching, assessment. Cambridge, GB: Cambridge University Press, 2001. Print.

CPNL (Consorci per a la Normalització Lingüística)."Memòria del CPNL 2012." (2012). Web. 15.5.2014. http://arxius.cpnl.cat/arxius/consadm/93/memoria2012_digital.pdf

CPNL (Consorci per a la Normalització Lingüística)."Memòria del CPNL 2014." (2014). Web. 05.5.2016. http://arxius.cpnl.cat/edicions/cnl/ memoria2014_doble.pdf

Etxezarreta, Miren. "La economía política del proceso de acumulación". Miren Etxezarreta (ed.). La reestructuración del capitalismo en España, 1970-1990. Barcelona: Icaria Editorial, 1991. 31-94. Impreso.

Etxezarreta, Miren, et al. "Boom and (Deep) Crisis in the Spanish Economy: The Role of the

EU in Its Evolution". Boletim de Ciencias Económicas, Núm. 55 (2012): 1-56. Impresso.

Galceran, Anna. "La Generalitat utilizará la televisión, la radio y la prensa para enseñar el catalán." El País, 1984. Web. 15.5.2014. http:// elpais.com/diario/1984/10/09/sociedad/466124403_850215.html

García Viamontes, Diosveni. "La globalización neoliberal. Sus consecuencias para la humanidad". Contribuciones a la Economía (2010). Web. 15.12.2015. http://www.eumed.net/ce/2010a/

Generalitat de Catalunya. Parla.cat. Barcelona: Direcció General de Política Lingüística, en col•laboració amb l'Institut Ramon Llull i el Consorci per a la Normalització Lingüística, 2008. Imprès.

Generalitat de Catalunya. "L'espai d'aprenentatge Parla.cat supera els 200.000 usuaris inscrits". 2016. Web. 05.5.2016. http://premsa. gencat.cat/pres_fsvp/AppJava/notapremsavw/291482/ca/lespaidaprenentatge-parla-cat-supera-200-000-usuaris-inscrits.do 
Gimeno, Montserrat. "La Direcció General de Política Lingüística i l'ensenyament de català per a adults. La perspectiva històrica, 1. L'enfocament comunicatiu i els processos d'innovació". Llengua i ús: revista tècnica de política lingüística, Núm. 51 (2012): 3-13. Imprès.

Hatcher, Richard and Niko Hirtt. "The business agenda behind Labour's education policy". Martin Allen et al. (eds.). Business business business: New labour's education policy. Londres: Tufnell Press, 1999. 12-33. Print.

Hirtt, Nico. "Markets and Education in the era of globalized capitalism". Dave Hill and Ravi Kumar (eds.). Global neoliberalism and education and its consequences. Nova York: Routledge, 2009. 208-226. Print.

Idescat (Institut d'Estadística de Catalunya). "Evolució de la població total i estrangera. 2000 - 2015. Catalunya." 2016. Web. 05.5.2016. http:// www.idescat.cat/poblacioestrangera/?b=0

Jódar, Francisco y Lucía Gómez. "Foucault y el análisis sociohistórico: sujetos, saberes e instituciones educativas". Revista Educación y Pedagogía, Vol. 15, Núm. 37 (2003): 55-68. Impreso.

Jódar, Francisco y Lucía Gómez. "Educación posdisciplinaria, formación de nuevas subjetividades y gubernamentalidad neoliberal". Revista Mexicana de Investigación Educativa, Vol. 12, Núm. 32 (2007): 381404. Impreso.

Kaščák, Ondreh and Branislav Pupala. "Governmentality-neoliberalismeducation: The risk perspective". Journal of Pedagogy/Pedagogický casopis, Vol. 2, Núm. 2 (2011): 145-158. Print.

Levidow, Les. "Marketizing higher education: Neoliberal strategies and counter-strategies". Wayne Ross and Rich Gibson (eds.). Neoliberalism and Education Reform. New Jersey, EUA: Hampton Press, 2006. 237-256. Imprès.

Littlejohn, Andrew. "The social location of language teaching: From zeitgeist to imperative". Azra Ahmed et al. (eds.). ELT in a Changing World. Cambridge, GB: Cambridge Scholars Publishing, 2013. 3-16. Web. 15.9.2015. www.AndrewLittlejohn.net

Llobera, Miquel, et al. Digui, digui... Curs de català per a no catalanoparlants adults 1. Llibre del professor (2a ed.). Montserrat-Barcelona: PAMSA i Enciclopèdia Catalana, 1989. Imprès.

Luke, Allen. "Teaching after the market. Ideology, curriculum, and the new sociology of education." Lois Weis, Cameron McCarthy and Greg Dimitriadis (eds.). Ideology, curriculum, and the new sociology of education: Revisiting the work of Michael Apple. New York: Routledge, 2006. 115-144. Print. 
Marí, Isidor. "El consell d'Europa i l'aprenentatge de llengües modernes". Butlletí de la Societat Catalana de Pedagogia (1986): 95-104. Imprès.

Mas, Marta, et al. Digui, digui... Curs de català per a no catalanoparlants adults. Primer nivell. Montserrat-Barcelona: PAMSA i Enciclopèdia Catalana, 1984. Imprès.

Mas, Marta, et al. Digui, digui... Curs de català per a no catalanoparlants adults. Segon nivell. Montserrat-Barcelona: PAMSA i Enciclopèdia Catalana, 1985. Imprès.

Mas, Marta, et al. Nivell llindar per a la llengua catalana. Barcelona: Generalitat de Catalunya, 1992. Imprès.

MECR. Marc europeu comú de referència per a les llengües: aprendre, ensenyar, avaluar. Barcelona: Generalitat de Catalunya, Govern d'Andorra i Govern de les Illes Balears, 2003. Web. 10.02.2013. http://llengua.gencat.cat/ca/serveis/informacio_i_difusio/publicacions_en_linia/classific_temes/temes_materials_didactics/marc_ europeu_de_referencia_per_a_les_llengues

O'Neill, Marnie. "Introduction." David Carter and Marnie O'Neill (eds.). International Perspectives on Educational Reform and Policy Implementation. Brighton, GB: Falmer, 1995. 1-14. Print.

Prodnik, Jerney A. "A seeping commodification: the long revolution in the proliferation of communication commodities". Triple C: Communication, Capitalism \& Critique. Journal for a Global Sustainable Information Society, Núm. 12, Vol. 1 (2014): 142-168. Print.

Rodríguez, Emmanuel, e Isidro López. "Del auge al colapso. El modelo financiero-inmobiliariode la economía española (1995-2010)". Revista de economía crítica, Núm. 12 (2011): 39-63. Impreso.

Selwyn, Neil. "The discursive construction of education in the digital age". Dins Rodney H. Jones, Alice Chik and Cristoph A. Hafner (eds.). Discourse and Digital Practices: Doing Discourse Analysis in the Digital Age. New York: Routledge, 2015. 226-240. Print.

Torras, Eulàlia. "Materials per a un primer curs de llengua catalana fora del domini lingüístic". Ponències, comunicacions i conclusions. Segon simposi sobre l'ensenyament del català a no catalano-parlants. Vic. 4, 5 i 6 setembre 1991. Vic: Eumo, 1992. 293-297. Imprès.

Torres, Jurjo. Educación en tiempos de neoliberalismo. Madrid: Ediciones Morata, 2001. Impreso.

Trim, John. "El català amb relació a Europa". Ponències, comunicacions i conclusions. Segon simposi sobre l'ensenyament del català a no catalanoparlants. Vic. 4, 5 i 6 setembre 1991. Vic: Eumo, 1992. 39-51. Imprès. 
Valax, Philippe. "The Common European Framework of Reference for Languages: A critical analysis of its impact on a sample of teachers and curricula within and beyond Europe". Tesi doctoral no publicada. University of Waikato, Australia, 2011. Web. 10.9.2015. http:// researchcommons.waikato.ac.nz/handle/10289/5546

Van Ek, Jan Ate. The Treshold Level. Estrasburg: Consell d'Europa, 1975. Imprès.

Virno, Paolo. Gramática de la multitud. Para un análisis de las formas de vida contemporáneas. Madrid: Traficantes de Sueños, 2003. Impreso.

\title{
Pau Bori
}

\section{THE DEVELOPMENT OF CATALAN AS A SECOND LANGUAGE TEXTBOOKS FROM A SOCIOECONOMIC PERSPECTIVE}

\begin{abstract}
Summary
This article presents the evolution of Catalan language teaching materials for immigrant adults linking their development with broader political, historical and socioeconomic issues. This study highlights two key moments in the history of Catalan textbooks. The first moment is in the 1980s, a time of great transformations in Spain after Franco's death and the accession to the European Economic Community. The most popular material at that time was the multimedia course Digui, Digui, elaborated by the Catalan government under the auspices of the Council of Europe. The second key moment brings us to the turn of the twenty-first century, when Spain experienced a fast economic growth based on the sectors of construction and tourism. This growth had its roots in the application of neoliberal economic policies and required cheap labour, which arrived from regions outside of Spain. This growing number of foreigners in Catalonia provoked a significant rise in students of Catalan as a second language. As a consequence, publishers of educational material increased their Catalan language teaching materials production. At the same time, however, these last years there has been a fast process of standardization, homogenization, and centralization of Catalan textbooks in the sense that they all have the same approaches: they follow the Common European Framework for Languages and propose the teaching of a practical language to serve the interests of the neoliberal economy.
\end{abstract}

Keywords: textbooks, Catalan as a second language, foreign language teaching, neoliberalism, immigration. 